\title{
FACTORS ASSOCIATED WITH USE OF VOLUNTARY COUNSELING TESTING SERVICE AMONG LESBIAN, GAY, BISEXUAL, TRANSGENDER GROUPS IN KUPANG
}

\author{
Sitti Hasnah Ema Abon'1), Rafael Paun²), Marthen Robinson Pellokila3) \\ 1)Commision for HIV/AIDS Control, Kupang \\ 2,3)Masters Program in Public Health, Nusa Cendana University
}

\begin{abstract}
Background: Lesbian, Gay, Bisexual, Transgander (LGBT) continu to grow rapidly in Kupang. LGBT is at high risk for Sexually Transmitted Infections (STI) and HIV/ AIDS. Voluntary Counseling Testing (VCT) service is provided by the government to screen and control STI and HIV/ AIDS among LGBTs. VCT is very important because it serves as an entrance to prevention and treatment of HIV and AIDS. However, only 18 LGBTs visited VCT in 2015. This study aimed to determine the factors associated with the use of VCT service by LGBT groups in Kupang.

Subjects and Method: This was a mixed qualitative and quantitative study with cross sectional design. This study was carried out in Kupang, East Nusa Tenggara, where the population of the LGBTs was 460 people. A sample of 210 LGBTs were selected by random sampling technique. The dependent variable was use of VCT. The independent variables were knowledge, intention, counselor empathy, counselor knowledge, and social support. The data were collected by questionnaire and analyzed using multiple logistic regression.

Results: Use of VCT was associated with knowledge (OR $=1.32 ; 95 \% \mathrm{CI}=-$ 0.54 to $3.18 ; \mathrm{p}=0.008)$, intention $(\mathrm{OR}=1.32 ; 95 \% \mathrm{CI}=-0.54$ to $3.18 ; \mathrm{p}=$ $0,010)$, counselor empathy $(\mathrm{OR}=1.38 ; 95 \% \mathrm{CI}=-0.48$ to $3.24 ; \mathrm{p}=0.081)$, counselor knowledge $(\mathrm{OR}=1.38 ; 95 \% \mathrm{CI}=-0.34$ to $3.24 ; \mathrm{p}=0.003)$, and social support $(\mathrm{OR}=1.25 ; 95 \% \mathrm{CI}=-0.61$ to $3.11 ; \mathrm{p}=0.037)$.
\end{abstract}

Conclusion: Use of VCT is associated with knowledge, intention, counselor empathy, counselor knowledge, and social support.

Keywords: Lesbian, Gay, Bisexual, Transgender, HIV, VCT

Correspondence: Sitti Hasnah Ema Abon, MKes. Commision for HIV/ AIDSControl, Kupang, East Nusa Tenggara. Email: nonahasnah@yahoo.co.id. Mobile: +628113911414 . 